\title{
PENGLIBATAN PERTUBUHAN SUKARELA WANITA DALAM PROGRAM PEMBANGUNAN SOSIOEKONOMI WANITA DI
} SABAH, 1968-1998

\section{The Involvement of Women's Voluntary Organizations in the Socio-} Economic Development Programme of Sabah Women, 1968-1998

\author{
${ }^{1}$ SITI AIDAH BINTI HJ. LUKIN @ LOKIN \\ ${ }^{2}$ ARBA'IYAH MOHD NOOR \\ Pusat Penataran Ilmu \& Bahasa, Universiti Malaysia Sabah, Jalan UMS, 88400 Kota Kinabalu. \\ Jabatan Sejarah, Universiti Malaya, 50603 Kuala Lumpur

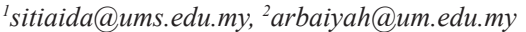 \\ Diterima: : 4 Jun 2017 / Dibaiki: 20 Julai 2018
}

\begin{abstract}
Abstrak Artikel ini memberi fokus kepada penglibatan pertubuhan sukarela wanita dalam program pembangunan sosioekonomi wanita di Sabah dari tahun 1968 sehingga 1998. Pertubuhan sukarela wanita yang dimaksudkan ialah Perkumpulan Perempuan Sabah (PPS) dan Pertubuhan Wanita Sabah (PEWASA), iaitu dua buah pertubuhan sukarela wanita yang terkenal di Sabah dan keahliannya terbuka kepada kaum wanita pelbagai etnik serta agama. Selepas kemerdekaan Sabah pada 1963, negeri ini telah menyaksikan pelbagai program yang dirancang oleh pihak kerajaan dalam pembangunan sosioekonomi masyarakat termasuklah usaha membangunkan kaum wanitanya. Dalam tempoh 1968-1998, PPS dan PEWASA begitu giat melibatkan kaum wanita dalam program-program pembangunan sosioekonomi wanita. Penglibatan kedua-dua pertubuhan sukarela wanita ini dalam pembangunan sosioekonomi wanita di Sabah dapat dikesan menerusi kegiatan-kegiatan yang dianjurkan oleh pertubuhan-pertubuhan ini dari semasa ke semasa meliputi program-program pembangunan wanita dalam bidang ekonomi, pendidikan dan kesihatan. Maklumat tentang penglibatan PPS dan PEWASA dalam program-program pembangunan sosioekonomi wanita ini diperoleh daripada laporan-laporan kegiatan pertubuhan, fail-fail persendirian, laporan akhbar dan temu bual dengan pemimpin pertubuhan berkenaan. Hasil kajian mendapati bahawa kedua-dua pertubuhan ini menjadi salah satu saluran penting yang memudahkan agenda pembangunan sosioekonomi pihak kerajaan sampai kepada kumpulan sasaran iaitu kaum wanita Sabah. Menerusi kajian ini juga akan dapat mengetengahkan kepada umum tentang penglibatan pertubuhan sukarela wanita dalam program
\end{abstract}


pembangunan sosioekonomi wanita di samping membantu pihak kerajaan dalam melaksanakan agenda pembangunan yang berterusan terhadap golongan wanita di Sabah.

Kata kunci: Pertubuhan sukarela, program pembangunan, sosioekonomi, Wanita Sabah.

Abstract This article focuses on the involvement of voluntary women organisations in socio-economic development programmes for women in Sabah from 1963 to 1998. The organisations focused on this article are Perkumpulan Perempuan Sabah (PPS) and Pertubuhan Wanita Sabah (PEWASA), two well-known voluntary women organisations in Sabah with their membership open to women from various ethnicities and religious beliefs. After independence in 1963, Sabah witnessed numerous government programmes to develop the socio-economy of various communities in Sabah including efforts to develop the women community. From 1968 to 1998, PPS and PEWASA actively encouraged women to participate in socioeconomic development programmes targeted for them. The involvement of these two organisations in developing the socio-economy of women are reflected in their activities such as development programmes economy, education, and health. Data related to PPS and PEWASA's involvement in these programmes were collected from reports on their activities, private files, newspaper reports, and interviews with their leaders or Executive Committee members. The findings reveal that these two organisations have become important channels which facilitate the development of the socioeconomy agenda planned and implemented by the government to reach the women community of Sabah. Through this study, the public is made aware of the involvement of voluntary women organisations in socio-economic development programmes for women and their support to the government in implementing a continuous agenda of developing the women community in Sabah.

Keywords: Voluntary organisations, development programmes, socioeconomy, Sabah Women. 


\section{PENDAHULUAN}

Pertubuhan sukarela wanita di Sabah tumbuh dan berkembang kesan daripada kemajuan yang dicapai oleh kaum wanita di Sabah terutamanya dalam bidang pendidikan. Peluang-peluang pendidikan yang dinikmati oleh sebilangan wanita khususnya di kawasan bandar mendorong mereka untuk melibatkan diri dalam kegiatan berpersatuan. Penglibatan tersebut bermula dengan kegiatan pasukan unit-unit beruniform di sekolah-sekolah hinggalah kepada kegiatan persatuan-persatuan sosiobudaya yang berkembang di bandar Jesselton (Kota Kinabalu) pada akhir tahun 1950-an. Pengalaman awal bergiat dalam persatuan-persatuan sosiobudaya ini mendorong kaum wanita berkenaan untuk menubuhkan pertubuhan sukarela yang anggotanya hanya terdiri daripada kaum wanita. Dengan adanya pertubuhan sukarela wanita, perjuangan mereka untuk menjurus kepada usaha-usaha pembangunan sosioekonomi wanita lebih terserlah, terarah dan berfokus. Kewujudan pertubuhan-pertubuhan sukarela wanita ini juga dimanfaatkan oleh pihak kerajaan sebagai salah satu saluran untuk memudahkan program-program pembangunan khususnya untuk wanita sampai kepada golongan sasaran yang ditetapkan. Makalah ini akan membincangkan bagaimanakah pertubuhan sukarela wanita yang terpilih, iaitu PPS dan PEWASA melibatkan diri dalam program-program pembangunan sosioekonomi di Sabah khususnya untuk meningkatkan status kaum wanitanya.

\section{Latar belakang Penubuhan PPS dan PEWASA}

Selepas Sabah mencapai kemerdekaan dan bersama-sama Tanah Melayu, Singapura dan Sarawak membentuk Malaysia pada 16 September 1963, ruang untuk kaum wanita bergiat dalam persatuan semakin terbuka. Penglibatan kaum wanita dalam persatuan-persatuan sosiobudaya dan partiparti politik awal seperti United National Kadazan Organisation (UNKO) dan United Sabah National Organisation (USNO) memberikan ruang yang lebih luas untuk mereka sering bertemu dan bertukar-tukar fikiran. Perkembangan kegiatan pertubuhan wanita di Semenanjung Malaysia, Sarawak dan di Brunei ternyata mempengaruhi kaum wanita Sabah untuk turut menubuhkan persatuan wanita yang serupa dengan pertubuhan wanita di negeri-negeri berkenaan. Pada bulan Mac 1967, rombongan Ahli 
Jawatankuasa Women Institute (WI), iaitu pertubuhan sukarela wanita di Semenanjung Malaysia telah mengadakan lawatan di Sabah sebagai salah satu kegiatan pertubuhan wanita berkenaan. Dalam lawatan tersebut, barisan kepemimpinan WI menggalakkan penubuhan persatuan wanita di Sabah serta bercadang untuk menjadikan persatuan berkenaan sebagai cawangan WI di Sabah. ${ }^{1}$

Kesan daripada lawatan tersebut dan perbincangan dengan pemimpin-pemimpin WI telah mendorong Toh Puan Hajah Rahma ${ }^{2}$ untuk menubuhkan persatuan wanita di Sabah. Pada tahun 1968, Toh Puan Hajah Rahma kemudiannya telah mengambil inisiatif mengadakan perbincangan dengan beberapa orang pemimpin wanita ${ }^{3}$ daripada kalangan kaum ibu parti USNO, kakitangan wanita dari Jabatan Ketua Menteri dan pemimpin wanita yang sebelum ini telah bergiat dalam persatuan yang ada di Sabah seperti Angkatan Gaya Baru (AGABA) pada tahun 1950-an. Perbincangan tersebut diadakan di rumah beliau sendiri di Tanjung Aru, Kota Kinabalu. Melalui perbincangan tersebut, mereka telah mencapai persetujuan untuk menubuhkan PPS. PPS kemudiannya didaftarkan oleh Jabatan Pendaftaran Pertubuhan Sabah pada 5 Februari 1971.

Sepanjang tempoh 1968 hingga 1976, PPS muncul sebagai persatuan wanita pertama yang dapat menggerakkan kaum wanita dalam kegiatan berpersatuan dan menyumbang kepada pembangunan serta pencapaian wanita dalam pelbagai bidang. Semangat kesukarelaan yang tinggi dan kerjasama yang erat dalam kalangan barisan kepemimpinan serta ahli persatuan menjadi aset penting dalam kejayaan PPS menganjurkan pelbagai aktiviti pada masa itu. Sokongan daripada kerajaan negeri, sama ada dari segi material dan sokongan moral menjadi faktor penting yang memudahkan PPS bergerak dalam usaha melibatkan wanita dalam persatuan sukarela dan program-program pembangunan wanita. Walau bagaimanapun, kegiatan dan perjuangan persatuan ini mula malap selepas kejatuhan parti USNO pada tahun 1976 kerana barisan kepemimpinan PPS dan ahli-ahlinya kebanyakannya juga daripada Kaum Ibu parti USNO. Dari tahun 1977, PPS tidak lagi bergiat aktif sehinggalah pendaftaran PPS digantung oleh Jabatan Pendaftaran Pertubuhan Sabah kerana tidak mengemukakan laporan minit mesyuarat agung, laporan kewangan dan laporan tahunan kegiatan 
persatuan dari tahun 1977 sehingga 1981 kepada jabatan berkenaan. ${ }^{4}$ Mesyuarat Agung PPS juga tidak dapat diadakan sejak tahun 1983 sehingga 1990. Penggantungan tersebut membawa kepada pembatalan PPS pada 28 Oktober 1991.

Pembatalan PPS itu tidak berterusan apabila adanya inisiatif daripada beberapa orang bekas pemimpin PPS dan tokoh-tokoh pemimpin wanita yang baharu dilibatkan dalam PPS untuk mendaftarkan kembali PPS dari tahun 1991 hingga 1995. Penglibatan Datuk Hajah Azizah Datuk Seri Panglima Haji Mohd. Dun ${ }^{5}$ sangat penting dalam menggerakkan jawatankuasa PPS menubuhkan PPS (Baru) yang dari segi tujuan penubuhannya adalah untuk meneruskan perjuangan PPS yang lama. PPS (B) telah didaftarkan semula pada 5 Disember 1995 dengan perubahan nama persatuan kepada Perkumpulan Perempuan Sabah Baru atau PPS (B). Sejak itu, PPS (B) telah menganjurkan pelbagai aktiviti yang dapat meningkatkan martabat kaum wanita dalam pelbagai bidang selaras dengan arus perkembangan semasa.

Ketika kegiatan dan perjuangan PPS mula malap iaitu setelah pucuk pimpinan kerajaan negeri beralih daripada Kerajaan USNO kepada Kerajaan Berjaya pada tahun 1976, muncul sebuah lagi pertubuhan sukarela wanita yang baharu iaitu Pertubuhan Wanita Sabah atau PEWASA. PEWASA ditubuhkan pada 24 Februari 1976 dan dirasmikan oleh Toh Puan Hajah Rahimah Stephens pada 22 Julai 1976. PEWASA kemudiannya didaftarkan oleh Jabatan Pendaftaran Pertubuhan Sabah pada 24 Februari 1978. Idea penubuhan PEWASA tercetus apabila Toh Puan Hajah Rahimah Stephens selaku Menteri Kebajikan Masyarakat Sabah memanggil beberapa orang kakitangan wanita Jabatan Ketua Menteri Sabah ${ }^{6}$ mengadakan mesyuarat bagi membincangkan sambutan Hari Wanita peringkat negeri Sabah. Dalam mesyuarat tersebut, mereka telah bersetuju untuk menubuhkan sebuah persatuan wanita bagi mengendalikan program Perayaan Hari Wanita peringkat negeri Sabah memandangkan pertubuhan wanita sebelum ini iaitu PPS tidak lagi bergiat aktif.

Sejak tahun 1976 sehingga 1987, PEWASA diberikan kepercayaan oleh Kerajaan Negeri Sabah sebagai penganjur sambutan Hari Wanita Peringkat Negeri Sabah dengan kerjasama pertubuhan-pertubuhan wanita 
lain yang ada di Sabah. Selepas lima tahun penubuhannya PEWASA telah berjaya melebarkan pergerakannya dengan penubuhan 25 buah cawangan di seluruh Sabah. Bilangan cawangan ini semakin bertambah seperti berikut: 1983: 25 cawangan, 1984: 30 cawangan, 1987: 49 cawangan, 1995: 60 cawangan dan pada tahun 2001, bilangan cawangan tersebut meningkat kepada 63 cawangan dengan bilangan ahli seramai 4000 orang di seluruh Sabah. ${ }^{7}$ Dari tahun 1976 sehingga tahun 1998, PEWASA telah melaksanakan pelbagai kegiatan dan memberikan sumbangan yang besar dalam proses pembangunan sosioekonomi wanita di Sabah.

\section{DAPATAN KAJIAN}

Penglibatan pertubuhan sukarela wanita yang terpilih dalam programprogram pembangunan sosioekonomi wanita di Sabah dapat ditinjau berdasarkan kegiatan PPS dan PEWASA dalam tiga bidang pembangunan sosioekonomi yang utama iaitu menerusi pembangunan ekonomi, pendidikan dan kesihatan. Dalam bidang ekonomi, fokus kegiatan pertubuhan sukarela wanita ini adalah untuk meningkatkan kemahiran wanita agar mereka boleh menjana pendapatan sendiri dan berpeluang menyertai kegiatan ekonomi yang sesuai dengan kemahiran mereka.

\section{Penglibatan dalam Program Kemahiran Ekonomi Rumah Tangga}

Selepas pembentukan Malaysia pada 16 September 1963, Kerajaan Sabah merancang dan melaksanakan pelbagai program pembangunan untuk mengurangkan kemiskinan dan sekali gus untuk meningkatkan taraf kaum wanita. Peningkatan kemahiran wanita dalam bidang ekonomi rumah tangga merupakan salah satu aspek yang difokuskan oleh kerajaan khususnya bagi membangunkan kaum wanita miskin di kawasan luar bandar. Sepanjang Rancangan Malaysia Ketiga, Kerajaan Negeri Sabah di bawah Kementerian Kebajikan Masyarakat dan Perpaduan Negara mengadakan lebih banyak Kursus Ekonomi Rumah Tangga (Kursus ERT) bagi meningkatkan taraf hidup rakyat serta mengurangkan kemiskinan dalam kalangan rakyat Sabah. Kursus ERT ini juga diselenggarakan oleh Bahagian Ekonomi Rumah Tangga, Jabatan Pertanian Sabah. Kursus ini diperluaskan pada 
peringkat kampung-kampung khususnya di kawasan luar bandar. Tujuan utama kursus tersebut diadakan adalah untuk memberikan pengetahuan asas kepada kaum wanita dalam urusan pengendalian sesebuah rumah tangga yang bahagia. ${ }^{8}$ Kursus tersebut berlangsung selama enam minggu dan antara pengisiannya adalah program ceramah-ceramah pembangunan ekonomi dan sosial, latihan praktikal (jahitan, kraf tangan dan sulaman, serta masakan), penjagaan kebersihan keluarga, pendidikan kesihatan untuk bayi dan keluarga, amalan perancang keluarga, pengurusan rumah tangga secara teratur, bercucuk tanam cara moden dan efektif serta amalan berjimat cermat dalam pengurusan ekonomi keluarga. ${ }^{9}$

Setelah PPS ditubuhkan pada tahun 1968, PPS mengadakan kelaskelas memasak dan menjahit untuk anak-anak gadis dan kaum wanita atau suri rumah yang datang dari luar bandar. Pada tahun 1974, lebih kurang 50 orang pelajar dari sekitar Kota Kinabalu, Tuaran, Tamparuli dan Putatan yang menghadiri kelas-kelas berkenaan di bangunan PPS, Sembulan. PPS juga telah menyediakan 22 buah mesin jahit untuk kegunaan mereka. ${ }^{10}$ Matlamat untuk membangunkan ekonomi wanita dan meningkatkan pendapatan keluarga cuba dicapai oleh PPS menerusi kegiatan meningkatkan kemahiran wanita melalui kursus-kursus urusan rumah tangga dan latihanlatihan kemahiran wanita yang dianjurkan dari semasa ke semasa.

Sebagai Ketua Kaum Ibu parti USNO, Toh Puan Hajah Rahma juga menggunakan cawangan-cawangan Kaum Ibu parti USNO sebagai saluran untuk memaklumkan kegiatan-kegiatan PPS dan meminta kerjasama daripada ketua-ketua cawangan Kaum Ibu USNO berkenaan mencari anak-anak gadis dan suri-suri rumah di kawasan mereka untuk mengikuti kursus-kursus kemahiran anjuran PPS itu. ${ }^{11}$ Kerjasama yang diberikan oleh cawangan-cawangan Kaum Ibu USNO ini memudahkan PPS menarik penyertaan daripada kaum wanita di sekitar daerah Kota Kinabalu dan Tuaran dalam program anjuran PPS itu. Penyertaan kaum wanita dalam kelas-kelas kemahiran ini dijalankan secara bergilir-gilir. Selepas tamat sesuatu sesi pembelajaran dalam tempoh tiga bulan, kumpulan wanita yang lain pula akan menggantikan tempat mereka. Kumpulan wanita yang telah menamatkan kursus pula berperanan untuk menyebarkan maklumat kepada wanita lain sama ada untuk hadir ke kursus kemahiran anjuran PPS atau 
pun kumpulan ini secara sukarela untuk meneruskan usaha membimbing kaum wanita di kampung mereka. Melalui cara ini kegiatan yang dianjurkan oleh PPS dapat digerakkan dan mendapat sambutan yang semakin meluas daripada kaum wanita di daerah Kota Kinabalu dan Tuaran.

Pada masa pemerintahan Kerajaan Berjaya di Sabah dari tahun 1976 hingga 1985, kursus ERT ini diberikan tumpuan yang penting sebagai usaha untuk membangunkan wanita di luar bandar. Kursus ERT ini dikendalikan oleh Kementerian Pembangunan Perindustrian dan Luar Bandar. Kursus kemahiran yang telah diadakan ialah kursus jahitan yang berjalan selama empat bulan di Pusat Pembangunan Masyarakat Kota Kinabalu. ${ }^{12}$ Sehingga bulan Julai 1978, kementerian tersebut telah berjaya melatih seramai 200 orang wanita termasuk 85 orang wanita dari luar bandar dalam bidang jahitan. Kursus jahitan ini membolehkan wanita yang telah memperoleh kemahiran memulakan kegiatan perniagaan secara kecil-kecilan di kampung mereka. Secara tidak langsung, perniagaan mengambil upah jahitan pakaian ini dapat menambah pendapatan keluarga mereka.

Pada peringkat awal, kursus-kursus ERT ini diadakan di daerah Kota Kinabalu kerana bandar Kota Kinabalu ialah ibu negeri Sabah yang memiliki kelebihan dari segi kemudahan asas berbanding kawasan luar bandar. Usaha pihak kerajaan untuk memperluaskan kursus-kursus kemahiran ini di peringkat luar bandar memerlukan kerjasama daripada pelbagai pihak termasuk daripada pertubuhan sukarela wanita yang sedia ada pada masa itu. Kebanyakan wanita di luar bandar adalah buta huruf dan kurang kesedaran untuk melibatkan diri dalam program-program pembangunan sosioekonomi wanita. Oleh itu, penglibatan PPS dan PEWASA sepanjang tempoh 1970an hingga 1990-an dalam membantu kerajaan khususnya Jabatan Pertanian melaksanakan Kursus ERT ini sangat penting. PEWASA khususnya pada peringkat cawangan bertindak selaku badan yang mengelolakan kursus berkenaan di kampung-kampung yang mempunyai cawangan PEWASA. PEWASA Bahagian Sandakan dan Bahagian Tawau terlibat secara aktif dalam pelaksanaan Kursus ERT ini.

Pada tahun 1980, PEWASA Cawangan Berhala Darat, Sandakan dengan kerjasama Jabatan Pertanian Sandakan, mengendalikan Kursus 
ERT kepada suri rumah di Kampung Berhala Darat. ${ }^{13}$ PEWASA Cawangan Tawau juga menganjurkan Kursus ERT ini pada 2 September hingga 30 Disember 1980. Kursus ini dihadiri oleh seramai 30 orang ahli PEWASA. Pelatih kursus datang daripada Jabatan Pertanian Tawau, tetapi pembiayaan sepanjang kursus ini dibiayai sepenuhnya oleh PEWASA Cawangan Tawau. Malah, tempat pengendalian kursus-kursus kemahiran ini diadakan di rumah-rumah AJK Tertinggi PEWASA Cawangan Tawau secara bergilirgilir. ${ }^{14}$ Kesediaan AJK Tertinggi PEWASA menjadikan rumah mereka sebagai tempat mengendalikan kursus-kursus ini membuktikan komitmen mereka dalam usaha menjayakan program meningkatkan kemahiran wanita yang menjadi salah satu aset penting bagi wanita untuk diintegrasikan dalam proses pembangunan sosioekonomi.

Kursus ERT tersebut diteruskan pada tahun 1990-an dan dari semasa ke semasa mengikut keperluan kemahiran yang diperlukan oleh kaum wanita di cawangan masing-masing. Pada tahun 1991, PEWASA Cawangan Sungai Kayu, Sandakan telah mengadakan kursus masakan dan kraf tangan, manakala PEWASA Cawangan Rancangan Sungai Manila, Sandakan pula mengadakan kursus jahitan pada tahun 1992. Kebanyakan cawangan PEWASA di bahagian Sandakan terlibat dalam program ERT dengan kerjasama Jabatan Pertanian Sandakan misalnya Cawangan Kampung Muhibah dan Cawangan Karamunting (1993) dan Cawangan Sekong (1995). Inisiatif cawangan yang terlibat mengemukakan permohonan kepada Jabatan Pertanian untuk melaksanakan kursus berkenaan di cawangan mereka membuktikan usaha pemimpin PEWASA peringkat cawangan begitu prihatin terhadap usaha meningkatkan kemahiran kaum wanita di kawasan masing-masing.

Penyertaan kaum wanita dalam kursus-kursus kemahiran ini membuktikan bahawa kaum wanita di luar bandar sebenarnya menyambut baik program-program pembangunan wanita jika maklumat yang tepat sampai kepada mereka menerusi saluran yang betul. Di sinilah pentingnya peranan pertubuhan sukarela wanita sebagai pencetus kesedaran dan pendorong kepada kaum wanita khususnya di luar bandar agar tidak terus terpinggir daripada arus kemajuan semasa. Usaha pertubuhan sukarela wanita seperti PEWASA menyalurkan maklumat yang tepat dan mengadakan program-program membimbing wanita untuk meningkatkan 
kemahiran mereka membuka ruang kepada kaum wanita yang terlibat meningkatkan status mereka.

Pada tahun 1991, 65.7 peratus kaum wanita di Sabah mendiami kawasan luar bandar. Mereka masih terlibat dalam kerja-kerja pengeluaran hasil pertanian, penternak, nelayan, berburu dan menghasilkan kraf tangan. ${ }^{15}$ Menyedari keadaan ini, pertubuhan sukarela wanita seperti PEWASA dan Perkumpulan Perempuan Sabah Baru (PPS(B)) memberi tumpuan kepada usaha membangunkan ekonomi wanita di luar bandar menerusi program yang sesuai dengan latar belakang kegiatan ekonomi mereka agar berlaku peningkatan pendapatan dalam kalangan wanita ini meskipun mereka terus menjalankan kegiatan ekonomi yang sama misalnya perniagaan secara kecil-kecilan. Pada tahun 1991, PEWASA telah mengadakan projek Industri Kampung bagi memproses makanan dan penghasilan kraf tangan di daerah Papar atas biayaan sebanyak RM25,000 oleh Associated Country Women of the World (ACWW).

Projek Industri Kampung anjuran PEWASA itu bertujuan untuk melatih kaum wanita khususnya suri rumah meningkatkan kemahiran mereka dalam pemprosesan makanan yang bahan-bahan asasnya mudah didapati di kawasan mereka. Projek ACWW Papar terbahagi kepada dua, iaitu pemprosesan makanan, kraf tangan dan jahitan serta latihan kepemimpinan. Melalui projek ini, kaum wanita yang terlibat dilatih dari segi pemprosesan makanan yang berkualiti, penetapan harga, urusan akaun perniagaan, kaedah pembungkusan yang selamat dan menarik serta kaedah pemasaran yang berkesan. Seramai 20 orang wanita telah dipilih untuk menyertai projek ini. Antara produk makanan yang dihasilkan ialah kerepek ubi, kerepek pisang, pecal dan rempeyek. Hasil kraf tangan pula ialah topi yang diperbuat daripada pandan, anyaman tikar mengkuang, jahitan manik dan labuci untuk selendang, sulaman motif untuk bingkai gambar dan sebagainya. Projek ini dipantau oleh PEWASA Cawangan Papar dan kaum wanita yang terlibat sentiasa dibimbing dan diberikan dorongan. Kesan daripada projek itu, wanita yang terlibat mampu berdikari, mempunyai sumber pendapatan sendiri dan terus aktif menghasilkan produk makanan tersebut serta memasarkannya di pelbagai tempat khususnya di tamu-tamu mingguan dalam daerah Papar. ${ }^{16}$ 
Projek industri kampung itu juga mendorong PEWASA Cawangan Papar terus aktif dalam meningkatkan kemahiran dalam pelbagai masakan dan kraf tangan. Antara program seterusnya yang dilaksanakan adalah seperti demonstrasi membuat kek pada 6 Mac 1993, demonstrasi menggubah bunga pada 10 Mac 1993, Pasar Ria pada 6 Jun 1993 dan demonstrasi membuat kek batik pada 19 Disember 1993. ${ }^{17}$ Kegiatan-kegiatan ini dianjurkan bagi membantu ahli-ahli PEWASA dan kaum wanita di daerah Papar melibatkan diri dalam program yang boleh menjana pendapatan mereka meskipun bermula sebagai peniaga hasil makanan secara kecil-kecilan.

Pertubuhan sukarela wanita juga menganjurkan pelbagai kegiatan bagi mendorong lebih ramai usahawan wanita di Sabah dapat dilahirkan. Pada peringkat cawangan PEWASA, sudah ada usaha-usaha untuk mencapai matlamat tersebut. Pada 24 September 1994, PEWASA cawangan Papar telah menganjurkan Seminar Kesedaran Pembangunan di balai raya Kampung Sepat, Papar. Para penceramah jemputan terdiri daripada pegawai Permodalan Nasional Berhad, Jabatan Pertanian dan Projek Usahamaju (PU), Koperasi Pembangunan Desa (KPD). Bagi membimbing kaum wanita yang mula menceburi bidang perniagaan secara kecil-kecilan, PEWASA Cawangan Papar juga telah mengadakan kursus yang berkaitan dengan pengurusan perniagaan iaitu Kursus Pengurusan Kira-kira Asas pada 19 Oktober 1995 sehingga 21 Oktober 1995 di pejabat Majlis Daerah Papar. ${ }^{18}$ Seminar keusahawanan pula telah dianjurkan oleh PEWASA pusat pada 2021 Oktober 1995 di Kota Kinabalu. Setiap cawangan PEWASA menghantar empat orang ahli sebagai wakil cawangan masing-masing menghadiri seminar berkenaan. Pada 26 Oktober 1997, PPS (B) menganjurkan Sesi Dialog "Peluang Meningkatkan Ekonomi Wanita" di Kota Kinabalu. Tokoh penting yang dijemput dalam dialog ini ialah Dato' Seri Rafidah Aziz, Menteri Perdagangan Antarabangsa.

Melalui sesi ceramah dan seminar yang dianjurkan oleh pertubuhan sukarela wanita ini, kaum wanita yang terlibat dalam bidang perniagaan didedahkan dengan peluang-peluang untuk memajukan perniagaan mereka. Menerusi kerjasama pertubuhan sukarela wanita dengan agensi-agensi kerajaan seperti Majlis Amanah Rakyat (MARA), Amanah Ikhtiar Malaysia (AIM) dan Projek Usahamaju (PU) dan Yayasan Usaha Maju (YUM) 
dalam ceramah dan seminar yang dianjurkan itu, kaum wanita yang terlibat dalam perniagaan secara kecil-kecilan dibimbing tentang cara mendapatkan modal untuk meneruskan dan mengembangkan perniagaan mereka. YUM merupakan sebuah institusi Kerajaan Negeri Sabah yang berperanan penting dalam membangunkan ekonomi wanita di Sabah.

Kerajaan Negeri Sabah menyedari kadar kemiskinan yang tinggi di Sabah berbanding negeri-negeri lain dalam Persekutuan Malaysia. Kadar kemiskinan di Sabah meningkat daripada 33.1 peratus pada 1984 kepada 35.3 peratus pada 1987. Oleh itu, Kerajaan Negeri Sabah komited terhadap usaha mengurangkan kadar kemiskinan menerusi pelbagai program pembangunan. Salah satu program pembangunan yang dilaksanakan ialah Projek Usahamaju (PU) yang dilancarkan pada bulan Jun 1988 di bawah kendalian Koperasi Pembangunan Desa (KPD), Kementerian Pertanian dan Industri Makanan Sabah bagi membantu mengurangkan kadar kemiskinan penduduk di luar bandar. ${ }^{19}$ PU kemudiannya diperluaskan ke seluruh negeri Sabah dan dinaik taraf menjadi Yayasan Usaha Maju (YUM) pada 30 Jun 1995.

Strategi utama YUM dalam mengurangkan kadar kemiskinan di Sabah adalah melalui perkhidmatan kredit mikro yang memberikan pinjaman secara kecil-kecilan kepada keluarga termiskin bagi membolehkan mereka mengusahakan kegiatan-kegiatan ekonomi yang menguntungkan dan mentransformasikan kumpulan sasaran termiskin di Sabah kepada satu kumpulan masyarakat yang berdikari. ${ }^{20}$ Sehingga bulan Julai 1991, seramai 2,376 orang menjadi ahli PU dan seramai 2,281 orang adalah peminjam wanita. ${ }^{21}$ Penglibatan kaum wanita dalam program PU dengan penyertaan yang tinggi sebanyak 99.29 peratus telah membuka satu dimensi baharu mewujudkan peluang-peluang perniagaan dan pekerjaan sendiri kepada sekelompok tenaga buruh wanita yang selama ini terpinggir dan tidak produktif. ${ }^{22}$ Dalam tempoh enam tahun (1990-1995), seramai 8,223 orang telah menyertai PU/YUM melibatkan 715 buah kampung di seluruh Sabah. Kawasan pedalaman mencatatkan bilangan peminjam modal tertinggi iaitu 54.2 peratus, kawasan barat selatan 44.7 peratus, kawasan timur 25.3 peratus, kawasan utara 21.8 peratus dan kawasan selatan Sabah sebanyak 12.6 peratus, manakala purata penyertaan tahunan adalah seramai 1,372 orang setahun. ${ }^{23}$ 


\section{Penglibatan dalam Program Pendidikan Wanita}

Di Sabah, masalah buta huruf dalam kalangan kaum wanitanya merupakan faktor yang menjadi penghalang kepada mereka untuk melibatkan diri dalam proses pembangunan. Kadar buta huruf wanita Sabah pada tahun 1960 ialah 43.6 peratus berbanding hanya 4.2 peratus yang celik huruf. Pada tahun 1970 pula, kadar buta huruf ialah 32.4 peratus berbanding 15.7 peratus yang celik huruf, manakala pada tahun 1980 pula, kadar buta huruf ialah 26.8 peratus berbanding 20.9 peratus yang celik huruf. ${ }^{24}$ Berdasarkan data tersebut, ternyata kadar buta huruf dalam kalangan kaum wanita di Sabah agak tinggi khususnya bagi tahun 1960. Malah, 90 peratus penduduk yang buta huruf itu tinggal di kawasan luar bandar. Meskipun sekolah-sekolah rendah dan menengah semakin banyak ditubuhkan oleh pihak kerajaan selepas kemerdekaan dicapai, usaha menyedarkan masyarakat tentang kepentingan pendidikan masih menghadapi cabaran yang besar khususnya di kawasan luar bandar. Masalah kekurangan kemudahan asas sering menyukarkan usaha-usaha pembangunan pendidikan, ditambah dengan masalah kekurangan tenaga guru serta kekangan dari segi nilai dan norma hidup tradisional masyarakat di luar bandar. Sering kali terjadi anak-anak tidak hadir ke sekolah apabila mereka terlibat membantu ibu bapa mereka melakukan sesuatu pekerjaan seperti menanam padi, menangkap ikan dan mencari hasil hutan untuk membiayai kehidupan keluarga mereka. ${ }^{25} \mathrm{Ibu}$ bapa yang buta huruf juga agak lambat mempunyai kesedaran tentang kepentingan pendidikan untuk masa depan anak-anak mereka.

Dalam konteks negeri Sabah pada zaman awal selepas kemerdekaan, usaha mengurangkan masalah buta huruf dalam kalangan penduduk dewasa menjadi keperluan utama. Penglibatan semua pihak termasuk komuniti setempat dan pertubuhan-pertubuhan sukarela sangat penting dalam usaha membantu kerajaan menyedarkan masyarakat khususnya penduduk di luar bandar tentang kepentingan bidang pendidikan dalam kehidupan mereka. PPS dalam era 1970-an menunjukkan keprihatinan terhadap masalah buta huruf khususnya dalam kalangan wanita dewasa ini. PPS telah mengendalikan kelas-kelas dewasa untuk mengajar kaum wanita yang buta huruf di bangunan PPS Sembulan. Anak-anak gadis, suri rumah dan kaum ibu yang buta huruf ini diajar dalam sebuah kelas 
yang terdiri daripada 20 hingga 30 orang pelajar. Mereka diajar menulis dan membaca. Pembelajaran mereka dianggap tamat setelah mereka boleh menguasai kemahiran membaca dan menulis. Kelas-kelas dewasa itu mendapat sambutan daripada kaum wanita di sekitar bandar Kota Kinabalu terutamanya penduduk di kawasan Tanjung Aru, Sembulan, Putatan dan daerah Tuaran. Selain menjalankan kegiatan mendidik kaum wanita dewasa menerusi kelas-kelas dewasa, usaha secara berterusan juga dilaksanakan oleh PPS menerusi pertemuan dan perbincangan dengan kaum wanita dalam majlis-majlis yang dianjurkan dari semasa ke semasa bagi menyedarkan kaum wanita, khususnya kaum ibu agar memberikan keutamaan kepada pendidikan anak-anak mereka.

Kemunculan PEWASA pada tahun 1978 mengembangkan lagi kelas-kelas buta huruf ini hingga ke kawasan luar bandar menerusi peranan yang dimainkan oleh cawangan-cawangannya di seluruh pelosok negeri Sabah. Cawangan-cawangan PEWASA mengendalikan kelas-kelas dewasa ini dengan melibatkan ahli-ahli PEWASA dan kaum wanita di sekitar kampung yang berhampiran dengan pusat kegiatan mereka, iaitu di balai-balai raya kampung atau di rumah AJK cawangan PEWASA. Bagi mendapatkan guru-guru yang berkelayakan mengajar di kelas-kelas dewasa ini, PEWASA menjalin kerjasama dengan agensi kerajaan seperti Kemajuan Masyarakat atau KEMAS. Misalnya, pada tahun 1987 beberapa cawangan PEWASA di daerah Sandakan yang begitu giat mengendalikan kelas-kelas dewasa ini ialah cawangan Berhala Darat, cawangan Taman Merpati dan cawangan Elopura. ${ }^{26}$

PEWASA juga tidak ketinggalan dalam usaha menyemai kesedaran kepada kaum wanita untuk terus menimba ilmu menerusi penganjuran majlis-majlis ilmu yang pengisiannya memberikan tumpuan kepada ceramah-ceramah kerjaya dan ceramah tentang peningkatan kualiti wanita dalam pelbagai bidang seperti kepemimpinan dan keterampilan diri. PEWASA pusat misalnya menganjurkan Kursus Berpidato di Kota Kinabalu pada 29 September 1986. Tujuan kursus ini diadakan adalah untuk memberi latihan kepada kaum wanita agar berani menyampaikan idea melalui kaedah yang betul dan berkesan serta petah menyampaikan ucapan. Kemahiran berpidato ini sangat perlu dalam konteks melatih dan 
menyediakan para pemimpin wanita yang berwibawa. Ramai daripada kalangan tokoh pemimpin politik dan perkhidmatan awam datang daripada ahli dan AJK PEWASA. ${ }^{27}$

PPS dan PEWASA ternyata telah memainkan peranan membantu kerajaan mengurangkan masalah buta huruf dalam kalangan wanita dan menyemai kesedaran dalam kalangan wanita khususnya untuk mengutamakan pendidikan anak-anak mereka. Kelas-kelas dewasa yang diadakan di luar bandar bagi memerangi buta huruf dalam kalangan wanita dan pendidikan tidak formal telah merintis perubahan baharu ke arah reformasi pendidikan untuk wanita. Proses sosialisasi keluarga, pergaulan dengan orang lain, pemerhatian dan perkongsian pengalaman, belajar daripada orang yang lebih berpengetahuan dan berkemahiran mengenai sesuatu yang penting dan sebagainya dapat membentuk rol dan peranan wanita. ${ }^{28}$

\section{Penglibatan dalam Program Pembangunan Kesihatan Wanita}

Penglibatan pertubuhan sukarela wanita dalam program-program pembangunan kesihatan wanita di Sabah boleh diteliti berdasarkan kerjasama pertubuhan berkenaan dengan Jabatan Kesihatan Negeri Sabah dan Jabatan Kesihatan pada peringkat daerah dalam pelaksanaan program-program kesihatan yang dianjurkan jabatan tersebut. PEWASA misalnya sama ada pada peringkat pusat mahupun cawangan sentiasa menyahut seruan kerajaan dalam pelaksanaan kempen-kempen kesedaran kesihatan. PEWASA sering menganjurkan program bagi memberi kesedaran kepada kaum wanita khususnya dan masyarakat amnya tentang penjagaan kesihatan yang baik, kesedaran tentang penyakit berjangkit dan penyakit kronik. Antara program yang dilaksanakan ialah mengadakan kursus, seminar, ceramah dan bengkel kesihatan untuk wanita dengan tujuan untuk memberikan kesedaran kepada kaum wanita dari peringkat remaja hinggalah kepada wanita dewasa tentang kepentingan penjagaan kesihatan daripada peringkat awal lagi. Selain melaksanakan program ceramah, bengkel, kursus dan seminar tentang kesihatan, PEWASA juga menggalakkan pelaksanaan program penjagaan kebersihan rumah, persekitaran rumah, perkampungan dan kawasan bandar. Program-program ini dilaksanakan bagi meningkatkan kesedaran wanita khususnya dan masyarakat terhadap penjagaan kebersihan alam sekitar. 
Antara program pelestarian kesihatan yang dianjurkan oleh PEWASA Pusat adalah seperti penganjuran ceramah-ceramah kesihatan misalnya Ceramah Umum osteoporosis pada 12 September 1991 di Hotel Shangri La, Tanjung Aru, Kota Kinabalu ${ }^{29}$ dan Forum Umum Post Menopousal Osteoporosis pada 24 Julai 1993 di Hotel Hyatt, Kota Kinabalu. ${ }^{30}$ Keduadua program ceramah dan forum tentang Osteoporosis itu ditaja oleh Farmasi Sandoz dan PEWASA Pusat berperanan sebagai jawatankuasa penganjur yang menguruskan persediaan dan perjalanan majlis. PEWASA Pusat meneruskan usaha menganjurkan seminar dan bengkel kesihatan untuk wanita. Antara seminar yang telah dianjurkan adalah Seminar Mengenai Putus Haid pada 27 Oktober 1996, Bengkel/Seminar mengenai Pemakanan pada 23-24 November 1996, anjuran bersama Majlis Penasihat Wanita Sabah (MPWS), Seminar on Healthy Mothers pada 21 Julai 1996 dan Seminar 'Menopause/Andropause: Satu Perubahan Alam Kehidupan Individu' pada 23 November 1996.

Pada peringkat cawangan pula, PEWASA cawangan Papar merupakan contoh cawangan PEWASA yang giat mengadakan pelbagai aktiviti yang berkaitan dengan penjagaan kesihatan wanita serta keluarga. Beberapa siri seminar, ceramah dan bengkel kesihatan telah diadakan dengan kerjasama Jabatan Kesihatan Daerah Papar. Antara seminar yang telah dianjurkan ialah Seminar ke Arah Kesihatan Wanita yang diadakan pada 30 Januari 1994 di Dewan Chung Hwa, Papar. Seminar ini dihadiri oleh 50 orang ahli PEWASA. Tujuan penganjuran seminar ini ialah memberi kesedaran kepada kaum wanita tentang pentingnya penjagaan kesihatan daripada peringkat awal lagi. Penceramah jemputan dalam seminar tersebut ialah Dr Suzain Datuk Hj. Suhaimi dan Dr Rahman dari Kota Kinabalu. Kursus Bidan Kampung anjuran bersama PEWASA dengan Jabatan Kesihatan Papar pula telah diadakan pada 22 Ogos 1996. Kursus tersebut telah mendedahkan para bidan kampung dengan kaedah perbidanan dan rawatan moden bagi menambah pengetahuan dalam kerjaya mereka agar kepakaran mereka terus diyakini oleh masyarakat. Pada bulan Disember 1996, Seminar Kesihatan Remaja diadakan di Bongawan, Papar. ${ }^{31}$ Menerusi ceramah ini, golongan remaja didedahkan dengan asas-asas penjagaan kesihatan di samping kesedaran agar tidak terlibat dalam gejala tidak sihat seperti merokok, penyalahgunaan dadah dan amalan seks bebas. 
Kempen Kesedaran Tentang Penyakit Berjangkit dan Penyakit Kronik juga dianjurkan oleh PEWASA Pusat dan cawangan-cawangan PEWASA secara berterusan. Kempen Kesedaran dan Pencegahan AIDS peringkat negeri Sabah telah dilancarkan oleh PEWASA dengan kerjasama NCWO pada 18 Januari 1992 di Centre Point, Kota Kinabalu. Pameran Pencegahan AIDS dan Forum Kesedaran AIDS turut dilaksanakan dalam kempen tersebut. Selain itu, Kempen Kesedaran Tentang Penyakit Barah Payudara dan Pangkal Rahim turut dilaksanakan oleh cawangan PEWASA di daerah Papar, Kota Kinabalu dan Sandakan dengan kerjasama klinikklinik kesihatan daerah dan Persatuan Jururawat Sabah. Dalam program ceramah, bengkel dan kursus kesihatan yang dianjurkan, PEWASA bertindak sebagai pelaksana yang menyediakan tempat, menguruskan penyertaan peserta, menyediakan peruntukan perbelanjaan bagi membiayai program berkenaan, manakala tenaga penceramah disediakan oleh Jabatan Kesihatan Daerah tempat program tersebut diadakan. Perkara ini membuktikan bahawa wujud kerjasama yang baik antara pertubuhan sukarela wanita dengan Jabatan Kesihatan. Kepemimpinan PEWASA walaupun hanya pada peringkat cawangan telah membantu mempercepatkan program-program pembangunan kesihatan sampai kepada kumpulan sasaran.

Kejayaan penganjuran program ceramah, forum, seminar dan bengkel kesihatan yang dianjurkan oleh PEWASA itu adalah disebabkan oleh kerja keras jawatankuasa PEWASA Pusat dalam memastikan program yang dianjurkan mendapat sambutan daripada kaum wanita yang menjadi kumpulan sasaran. Sambutan dan penglibatan kaum wanita dalam setiap program yang dianjurkan oleh PEWASA adalah sangat menggalakkan. Kehadiran para peserta sama ada daripada kalangan ahli PEWASA sendiri ataupun orang perseorangan sentiasa mencapai sasaran yang ditetapkan oleh PEWASA sebagai pihak penganjur. Biasanya jika sesuatu program itu dianjurkan oleh PEWASA Pusat, sasaran kehadiran peserta ialah seramai 100 hingga 300 orang, bergantung kepada kesesuaian lokasi program berkenaan. Jika program berkenaan diadakan di dewan masyarakat dan dewan hotel yang besar, sasaran penyertaan dalam lingkungan 200 hingga 300 orang peserta biasanya dapat dicapai. ${ }^{32}$ Kaum wanita di Sabah menyambut baik dan memberikan sokongan kepada program-program yang dianjurkan oleh PEWASA kerana PEWASA membuka keahlian dan penyertaan dalam 
mana-mana program yang dianjurkan kepada segenap lapisan wanita. Yuran penyertaan percuma dan makan minum peserta yang disediakan secara percuma juga menjadi tarikan kepada penyertaan ramai kaum wanita. Di samping itu, jaringan kerja yang luas antara PEWASA dengan Jabatan Kesihatan, MPWS, NCWO dan badan swasta juga menyumbang kepada kejayaan program pelestarian kesihatan yang dianjurkan. Bilangan doktor perubatan di Sabah masih tidak mencukupi jika dibandingkan dengan jumlah penduduk yang ada. Nisbah seorang doktor dengan bilangan penduduk adalah 1:13,100 (1963), 1:8,947 (1975), 1:6,075 (1980) dan 1:4,308 (1988). ${ }^{33}$ Oleh itu, peranan yang dimainkan oleh pertubuhan sukarela wanita seperti PEWASA membantu Jabatan Kesihatan dan pihak kerajaan umumnya dalam melaksanakan program pembangunan kesihatan untuk wanita dan masyarakat harus diberikan pujian dan penghargaan.

\section{KESIMPULAN}

PPS dan PEWASA telah terlibat secara aktif dalam program-program pembangunan sosioekonomi wanita di Sabah. Dalam tempoh 1968-1998, pertubuhan-pertubuhan sukarela wanita berkenaan telah banyak membantu pihak kerajaan melaksanakan program-program pembangunan untuk wanita dalam bidang ekonomi, pendidikan dan kesihatan. Pertubuhan sukarela wanita ini berperanan sebagai rakan kongsi kerajaan dalam melaksanakan program-program pembangunan sosioekonomi dan bagi memastikan matlamat pembangunan sosioekonomi wanita sampai kepada kumpulan sasaran khususnya kaum wanita di kawasan luar bandar. Penganjuran kegiatan-kegiatan pertubuhan sukarela wanita dengan kerjasama agensi kerajaan dan swasta sama ada pada peringkat pusat ataupun pada peringkat cawangan yang terdapat di seluruh Sabah ternyata telah mendorong kaum wanita untuk melibatkan diri dalam program-program pembangunan sekali gus dapat meningkatkan status wanita. 


\section{NOTA}

1 Sebelum lawatan tersebut WI telah pun meluahkan hasrat berkenaan menerusi surat daripada Kamsiah Wahab (Setiausaha WI) kepada Puan Zainon Suhaimi (AJK Penaja PPS) yang bertarikh 27 Mac 1967.

2 Toh Puan Hajah Rahma ialah Ketua Kaum Ibu USNO. Beliau juga ialah isteri kepada Tun Datu Mustapha bin Datu Haron, Presiden USNO dan Ketua Menteri Sabah ketika PPS ditubuhkan.

3 Antara pemimpin awal PPS (selain Toh Puan Hajah Rahma) yang menjadi jawatankuasa penaja PPS ialah Betty Lind (isteri Tan Sri Richard Lind), Bandong Hasbollah (isteri Tun Mohd. Said Keruak), Rufiah Haris (isteri Datuk Harris Mohd. Salleh), Zainon Suhaimi dan Hasnah Edinin (Bekas AJK Wanita AGABA). Fail No.WI/68/6, Senarai AJK Penaja PPS, Fail Setiausaha PPS, Pejabat PPS, Sembulan.

4 Surat Penolong Pendaftar, Jabatan Pendaftaran Pertubuhan Sabah, Look Sui Fong kepada Norliah Abdul Jalil, Setiausaha PPS, 13 November 1981.

5 Datuk Hajah Azizah bte Datuk Seri Panglima Haji Mohd. Dun ialah seorang tokoh politik wanita yang penting di Sabah. Beliau ialah seorang peguam sebelum terlibat sepenuhnya dalam bidang politik. Beliau pernah menjadi ADUN Klias, Ahli Parlimen Beaufort dan pernah memegang jawatan sebagai timbalan menteri di peringkat persekutuan dan menteri dalam kabinet negeri Sabah.

6 Barisan kepemimpinan PEWASA pada awal penubuhannya kebanyakannya daripada kalangan kakitangan wanita Jabatan Ketua Menteri Sabah. Antara tokoh wanita yang terlibat dalam penubuhan awal PEWASA ialah Datuk Ariah Tengku Ahmad (Presiden 1976-1977), Masrah Abidin (Timbalan Presiden), Jovinia Solibun (Setiausaha) dan Ahli Jawatankuasanya terdiri daripada Helena Kwan, Monica Kong, Josie Perkins, Nancy Yew dan Noni Said.

7 Laporan Kegiatan PEWASA Tahun 2001.

8 Daily Express, 2 Mac 1978.

9 Ibid.

${ }^{10}$ Laporan Kegiatan PPS dalam Minit Mesyuarat Agung PPS bertarikh 12 September 1974.

${ }^{11}$ Temu bual dengan Puan Norliah Abdul Jalil (Setiausaha PPS) pada 14 Februari 2012, di Pejabat PPS, Bangunan PPS, Sembulan, Kota Kinabalu.

${ }^{12}$ Daily Express, 22 Julai 1978.

${ }^{13}$ Sabah Times, 27 Mei 1980.

${ }^{14}$ Laporan Kegiatan PEWASA Cawangan Tawau 1980/81.

${ }^{15}$ Nancy Ho, 'Role of SWEPA in Women Entrepreneurship Development in Sabah', kertas kerja yang dibentangkan dalam seminar 'Women and Entrepreneur' anjuran Institute For Development Studies (IDS), pada 20-21 April 1998 di Shangri-La Tanjung Aru Resort, Kota Kinabalu, hlm.8.

${ }^{16}$ Report on ACWW Sponsored Project, By Bibi Florina Abdullah, PEWASA.

${ }^{17}$ Laporan Aktiviti PEWASA Cawangan Papar 1991-1995.

${ }^{18}$ Ibid.

${ }^{19}$ PU mencontohi Grameen Bank dengan pengubahsuaian berdasarkan keadaan penduduk tempatan di Sabah dari segi keadaan kemiskinan, peluang ekonomi, infrastruktur dan struktur sosiopolitik di Sabah. PU bukannya sebuah bank atau mempunyai pertalian dengan mana-mana bank, sebaliknya projek yang dilaksanakan oleh Kerajaan Negeri Sabah di bawah agensi kerajaan negeri iaitu KPD. PU tidak mengenakan faedah kepada peminjam 
tetapi hanya mengenakan bayaran perkhidmatan sebanyak 7\% daripada setiap pinjaman yang diambil oleh peminjam. Richard S. Gunting \& Freddy Rantau, 'Projek UsahamajuFrom Action Research to Institutionalization :Problem in Prospects', Regional Workshop on The Grameen Bank Approach to Poverty Alleviation: Experiences and Prospects in Asia. 25-28 August 1991, Perkasa Hotel Kundasang, Jointly organised by Institute For Development Studies Sabah (IDS) and Asian And Pacific Development Centre (Kuala Lumpur), hlm. 2-3.

${ }^{20}$ Kumpulan sasaran YUM ialah penduduk miskin di luar bandar terutamanya para wanita yang terdiri daripada suri rumah, ibu tunggal, peniaga kecil-kecilan, petani, nelayan dan usahawan kecil yang memerlukan modal bagi mengusahakan kegiatan-kegiatan ekonomi yang boleh menjana pendapatan. Freddy Rantau, 'Strategi-strategi Ke Arah Memantapkan Prestasi Yayasan Usaha Maju', dalam Isu-isu dan Strategi-strategi dalam Pembangunan Yayasan Usaha Maju, Prosiding Persidangan Yayasan Usaha Maju yang diadakan di Keningau Sabah pada 2-5 Disember 1996, hlm.31.

${ }^{21}$ Richard S. Gunting \& Freddy Rantau, 'Projek Usahamaju - From Action Research to Institutionalization: Problem in Prospects', Regional Workshop on The Grameen Bank Approach to Poverty Alleviation: Experiences and Prospects in Asia. 25-28 August 1991, Perkasa Hotel Kundasang, Jointly organised by Institute For Development Studies Sabah (IDS) and Asian And Pacific Development Centre (Kuala Lumpur), hlm. 4-5.

${ }^{22}$ Roseli Sindong, 'Prestasi Yayasan Usaha Maju dari 1990-1995: Satu Penilaian' dalam Isu-isu dan Strategi-strategi Dalam Pembangunan Yayasan Usaha Maju, Prosiding Persidangan Yayasan Usaha Maju yang diadakan di Keningau Sabah pada 2-5 Disember 1996, hlm.21.

${ }^{23}$ Ibid., hlm. 5.

${ }^{24}$ Banci Penduduk Negeri Sabah 1960, 1970, 1980, Kota Kinabalu: Jabatan Perangkaan Sabah.

${ }^{25}$ Hairi Abdullah, 'Struktur Pendidikan: Masalah dan Prospek dalam Pembangunan Tenaga Manusia' dalam Hairi Abdullah et al. (Penyunting), Integrasi Sabah, Bangi: Universiti Kebangsaan Malaysia, 1989, hlm. 62.

${ }^{26}$ Majalah PEWASA Cawangan Taman Merpati, Batu 7, Sandakan, 1988, hlm. 22.

${ }^{27}$ Antara pemimpin wanita dalam bidang politik Sabah yang datang daripada PEWASA ialah Datuk Ariah Tengku Ahmad, Datuk Dayang Mahani Tun Pangeran Ahmad Raffae, Datuk Jainab Ahmad Ayid, Datuk Hamisah Samat, Datuk Surinam Sadikun, Datuk Armani Mahiruddin dan Datuk Rosnah Rashid Shirlin. Tokoh wanita dalam perkhidmatan awam pula ialah Puan Jovinia Solibun, Datuk Adeline Leong, Datuk Noni Said, Datuk Maznah Ghani dan Puan Subiah Laten

${ }^{28}$ WANITA MALAYSIA Membela Maruah, Kuala Lumpur: Kementerian Pembangunan Wanita, Keluarga dan Masyarakat, 2010, hlm. 64.

${ }^{29}$ Ceramah ini diadakan secara kerjasama antara PEWASA Pusat dengan Farmasi Sandoz. Ceramah ini dihadiri oleh 300 orang wanita daripada kalangan ahli PEWASA dan wanita sekitar Bandar Kota Kinabalu. Laporan Aktiviti Biro-biro PEWASA Pusat 1991-1995, hlm. 2.

${ }^{30}$ Ibid., hlm.5.

${ }^{31}$ Laporan Aktitivit PEWASA Cawangan Papar 1995.

32 Temu bual dengan Puan Hanizah Abdullah (Presiden PEWASA) pada 18 Februari 2012, di Pejabat PEWASA Kota Kinabalu. 
${ }^{33}$ Michael K.C. Chan \& Goh Peng Peng, 'Development in Health Services in Sabah 1963-1988', dalam Jeffrey Kitingan \& Maximus J. Ongkili (Editor) Sabah 25 Years Later 1963-1988, Kota Kinabalu: Institute For Development Studies Sabah (IDS), 1989, hlm. 235.

\section{RUJUKAN}

Banci Penduduk Negeri Sabah (1960). Jabatan Perangkaan Sabah.

Banci Penduduk Negeri Sabah (1970). Jabatan Perangkaan Sabah.

Banci Penduduk Negeri Sabah (1980). Jabatan Perangkaan Sabah.

Buku Tahunan Perangkaan Sabah (2002). Jabatan Perangkaan Malaysia, Negeri Sabah.

Daily Express, 2 Mac 1978.

Daily Express, 17 April 1978.

Daily Express, 22 Julai 1978.

Fail No.WI/68/6, Senarai AJK Penaja PPS, Fail Setiausaha PPS, Pejabat PPS, Sembulan.

Freddy Rantau. (1996). Strategi-strategi ke arah memantapkan prestasi Yayasan Usaha Maju. Dlm. Isu-isu dan Strategi-strategi Dalam Pembangunan Yayasan Usaha Maju. Prosiding Persidangan Yayasan Usaha Maju yang diadakan di Keningau Sabah pada 2-5 Disember 1996.

Hairi Abdullah. (1989). Struktur pendidikan: Masalah dan prospek dalam pembangunan tenaga manusia. Dlm. Hairi Abdullah et al. (Ed.). Integrasi Sabah. Bangi: Universiti Kebangsaan Malaysia.

Laporan Aktiviti Biro-biro PEWASA Pusat 1991-1995.

Laporan Aktiviti PEWASA Cawangan Papar 1991-1995.

Laporan Aktiviti PEWASA Cawangan Papar 1995.

Laporan Kegiatan PEWASA Cawangan Tawau 1980/81.

Laporan Kegiatan PEWASA Tahun 2001.

Majalah PEWASA Cawangan Taman Merpati, Batu 7, Sandakan, 1988.

Michael K.C. Chan \& Goh Peng Peng. (1989). Development in health services in Sabah 1963-1988. Dlm. Jeffrey Kitingan \& Maximus J. Ongkili (Ed.). Sabah 25 years later 1963-1988. Kota Kinabalu: Institute For Development Studies Sabah (IDS).

Minit Mesyuarat Agung PPS bertarikh 12 September 1974.

Nancy Ho. (1998). Role of SWEPA in women entrepreneurship development in Sabah. kertas kerja yang dibentangkan dalam Seminar 'Women and Entrepreneur' anjuran Institute for Development Studies (IDS), pada 20-21 April 1998 di Shangri-La Tanjung Aru Resort, Kota Kinabalu.

Report on ACWW Sponsored Project, by Bibi Florina Abdullah, PEWASA. 
Richard S. Gunting \& Freddy Rantau. (1991). Projek Usahamaju - From action research to institutionalization: Problem in prospects. Regional workshop on The Grameen Bank approach to poverty alleviation: Experiences and prospects in Asia. 25-28 August 1991, Perkasa Hotel Kundasang, Jointly organised by Institute For Development Studies Sabah (IDS) and Asian And Pacific Development Centre (Kuala Lumpur).

Roseli Sindong. (1996). Prestasi Yayasan Usaha Maju dari 1990-1995: Satu Penilaian. Dlm. Isu-isu dan Strategi-strategi dalam Pembangunan Yayasan Usaha Maju, Prosiding Persidangan Yayasan Usaha Maju yang diadakan di Keningau Sabah pada 2-5 Disember 1996.

Sabah Times, 27 Mei 1980.

Surat Kamsiah Wahab (Setiausaha WI) kepada Puan Zainon Suhaimi (AJK Penaja PPS), 27 Mac 1967.

Surat Penolong Pendaftar, Jabatan Pendaftaran Pertubuhan Sabah, Look Sui Fong kepada Norliah Abdul Jalil, Setiausaha PPS, 13 November 1981.

WANITA MALAYSIA Membela Maruah. (2010). Kuala Lumpur: Kementerian Pembangunan Wanita, Keluarga dan Masyarakat.

Temu bual bersama Puan Hanizah Abdullah, Presiden PEWASA, 18 Februari 2012. Pejabat PEWASA Kota Kinabalu.

Temu bual bersama Puan Norliah Abdul Jalil, Setiausaha PPS, 14 Februari 2012, Pejabat PPS, Kota Kinabalu. 